\title{
The use of indicators for the management of Mental Health Services
}

\author{
Inacia Bezerra de Lima ${ }^{1,2}$ \\ (1) https://orcid.org/0000-0003-3580-3244 \\ Filipe Andrade Bernadi ${ }^{3}$ \\ (D) https://orcid.org/0000-0002-9597-5470 \\ Diego Bettiol Yamada ${ }^{2,4}$ \\ (D) https://orcid.org/0000-0001-6221-722X \\ Andre Luiz Teixeira Vinci ${ }^{4}$ \\ (iD) https://orcid.org/0000-0003-3743-0250 \\ Rui Pedro Charters Lopes Rijo ${ }^{5}$ \\ (D) https://orcid.org/0000-0002-9348-0474 \\ Domingos Alves 4 \\ (1D) https://orcid.org/0000-0002-0800-5872 \\ Antonia Regina Ferreira Furegato \\ (D) https://orcid.org/0000-0002-7901-2965
}

Universidade de São Paulo, Escola de Enfermagem de Ribeirão Preto, PAHO/WHO Collaborating Centre for Nursing Research Development, Ribeirão Preto, SP, Brazil.

2 Scholarship holder at the Coordenação de Aperfeiçoamento de Pessoal de Nível Superior (CAPES), Brazil.

3 Universidade de São Paulo, São Carlos, SP, Brazil.

${ }^{4}$ Universidade de São Paulo, Faculdade de Medicina de Ribeirão Preto, Ribeirão Preto, SP, Brazil.

5 Instituto Politécnico de Leiria, Escola de Tecnologia e Gestão, Leiria, Leiria, Portugal.

\begin{abstract}
Objective: to identify indicators that can be used in the management of Mental Health Services. Method: an integrative review in which we adopted the Population, Concept, and Context strategy to formulate the following Guiding Question: "Which indicators can be used for the management of mental health services?". Results: a total of 22 articles were included and divided into two main groups: countries with initial high income (54\%) as well as low- and middle-income countries (46\%). We identified 5 studies that had experienced the use of indicators, 5 studies that had reported partial implementation, 9 studies that did not report use or implementation, 1 study on the indicator selection process, 1 as an implementation pilot, and a final study with a discussion for implementation. High-income countries also find it difficult to implement mental health indicators. The main difficulties in adopting the use of indicators are lack of basic mental health services, financial resources, legislation, political interest, and guidelines for its management. Conclusion: it is unusual to find a descriptive comparison of quality monitoring programs at the system level in the technical-scientific literature related to mental health indicators.
\end{abstract}

Descriptors: Health Status Indicators; Public Health Administration; Mental Health Services; Health Services Administration; Health Care Quality Indicators; Health Planning Guidelines.

\section{How to cite this article}

Lima IB, Bernardi FA, Yamada DB, Vinci ALT, Rijo RPCL, Alves D, Furegato ARF. The use of indicators for the management of Mental Health Services. Rev. Latino-Am. Enfermagem. 2021;29:e3409. [Access $\frac{1}{f} \frac{1}{1}$; Available in: DOI: http://dx.doi.org/10.1590/1518-8345.4202.3409. 


\section{Introduction}

The World Health Organization (WHO) has set four priority objectives in its Mental Health Action Plan 2013$2020^{(1)}$ : strengthen effective leadership and governance for Mental Health (MH); provide comprehensive, integrated and responsive mental and social health services in community settings; implement strategies for promotion and prevention in $\mathrm{MH}$; and strengthen information systems, evidence and research for $\mathrm{MH}^{(1-2)}$. One of the principles for achieving these WHO goals is the use of indicators that are important for monitoring MH systems data. The WHO recommends that $80 \%$ of all countries collect and report at least one core set of Mental Health Indicators (MHIs) and that this action should happen through their national health and social information systems by the year 2020(3). Moreover, it also provides a set of key indicators to assess the levels of implementation, progress, and impact of defined targets. After the publication of the action plan, the WHO launched the Mental Health Atlas of 2014 and 2017 to monitor the progress of countries in achieving the established targets ${ }^{(4-5)}$.

More than 450 million people are afflicted by mental illness and the global burden of mental illness is underestimated. Recent research suggests that this burden accounts for $32.4 \%$ of years lived with disability and $13.0 \%$ of disability-adjusted life-years. This is a particular concern in low- and middle-income countries (LMICs) where more than $70 \%$ of the mental illnesses $\operatorname{occur}^{(6)}$.

In the last two decades, there have been a large number of publications and reviews on the use of $\mathrm{MH}$ guidelines ${ }^{(7-8)}$. Despite the proliferation of evidence-based guidelines for the treatment of mental disorders, there is no consensus as to which recommendations should be used $^{(9)}$. A set of indicators should follow expected patterns of use, along with relevant and necessary data, in addition to validity accuracy to inform the merits of the evaluated practices and processes ${ }^{(10)}$. There were a limited number of "evaluative indicators" in $\mathrm{MH}$ related findings to record or measure properties, process, and interpretation of use and outcomes ${ }^{(10-11)}$.

This scenario shows the lack of focus on this aspect prior to the publication of the WHO's Mental Health Action Plan from 2013 to 2020, and that it is now necessary to know the possible progress derived from the action based on such a document.

In spite of the WHO's recommendations, it is possible to find in the literature differences in the groups of indicators, the name of the indicators, how they are defined and which category each one belongs to ${ }^{(1,12)}$. Thus, it is important to seek evidence on the indicator's performance for $\mathrm{MH}$ management based on the experience of use analysis, highlighting the differences and consensus of interpretations. In this way, we will carry out an integrative review of the technical-scientific literature, with the main objective of identifying indicators that can be used for the management of $\mathrm{MH}$ services. In this study, we will also analyze the evolution of $\mathrm{MH}$ services in different contexts and countries, the development of indicators and the progress of their implementation. Finally, it is important to highlight that this study is part of an international multicenter study, involving researchers from Brazil and Portugal.

\section{Method}

This Integrative Review study was prepared according to the method described in the Joanna Briggs Institute Reviewers' Manual 2015 - JBISRIR(13-14). The study mapped the main concepts, allowing for the clarification areas of research and identifying knowledge gaps. This can be done through an assessment of feasibility, significance, and adequacy of the recommended health care practice. In our scenario, this is fundamental to understand the evolution and state of the art of MHI services in different contexts and countries.

This Integrative Review is, however, not in itself a normative contribution. It does not aim to propose or argue for what core indicators and values should guide MHIs, though the importance of such work is emphasized. Instead, the Integrative Review has a descriptive and analytic function. It seeks to provide an overview of what issues have emerged on MHIs and what guidance exists on how to address them and inform ongoing efforts to develop meaningful and comprehensive guidelines for the practice.

A structure of six topics was proposed: (1) Identifying the research guiding question (GQ); (2) Identifying relevant studies; (3) Selecting studies; (4) Data selection and storage; (5) Collating, summarizing and reporting results; and (6) Results Analysis - Discussion ${ }^{(15) .}$

1: Identifying the research $G Q$. To fulfill the requirements of the integrative review, the research GQ must adequately establish the fundamental evidence for the argument in the GQ. It should also determine the incorporation of the analysis, promoting the amount of information in the databases, with fewer unnecessary searches $^{(13)}$.

To construct the research $\mathrm{GQ}$, we adopted the Population, Concept and Context (PCC) strategy. With this strategy, in this study, we formulated the following GQ: "Which indicators can be used for the management of MH services?", where Population refers to the MHIs, 
Concept refers to the use in management, and Context refers to the $\mathrm{MH}$ services.

It should be emphasized that the population may include the articles selected for inclusion and must be related to the objectives of the integrative review. The Concept should be clearly articulated for the integrative character and breadth of the survey. The Context should be clearly defined and can include considerations of cultural factors, such as geographic location and/or specific racial or gender interests. In some cases, the context may also cover details about specific scenarios such as the health care system(15).

The framework suggests a broad, clearly articulated research GQ, defining concepts, target population, health outcomes, and integrative, whilst also accounting for the aim and rationale of the review ${ }^{(15)}$.

2: Identifying relevant studies. A search was performed in the following databases: Web of Science, National Library of Medicine - PubMed, Science Direct, MEDLINE and Scopus. Furthermore, additional searches were made in databases with the majority of papers being in the Portuguese and Spanish languages, namely, Scientific Electronic Library Online (SciELO) and Latin-American and Caribbean System on Health Sciences Information (LILACS). In these searches, we used the selected keywords and a translation of the selected descriptors by the Health Sciences Descriptors ${ }^{(16)}$.

3: Selecting studies. The search procedure was oriented in accordance with the combination of keywords derived from the PCC strategy of this study and controlled and uncontrolled descriptors from Medical Subject Headings - MESH, a dictionary of controlled vocabulary synonyms for indexing articles(16). For the combination of such terms, we considered the Boolean operators AND, OR and NOT to compose the search queries in the referred databases, following the inclusion and exclusion criteria. Within the PCC strategy, the search controlled descriptors were the following: Population (P): "Quality Indicators, Health Care" OR "Health Status Indicators" OR "Health Planning Guidelines". Uncontrolled descriptors for Population: "Quality Indicators, Healthcare" OR "Healthcare Quality Indicator" OR "Healthcare Quality Indicators" OR "Indicator, Healthcare Quality" OR "Indicators, Healthcare Quality" OR "Quality Indicator, Healthcare" OR "Global Trigger Tool, Healthcare" OR "Healthcare Global Trigger Tool" OR "Health Status Indicator" OR "Indicator, Health Status" OR "Indicators, Health Status" OR "Health Status Index" OR "Health Status Indices" OR "Index, Health Status" OR "Indices, Health Status" OR "Health Status Indexes" OR "Indexes, Health Status" OR "Health Risk Appraisal"
OR "Appraisal, Health Risk" OR "Appraisals, Health Risk" OR "Health Risk Appraisals" OR "Risk Appraisal, Health" OR "Risk Appraisals, Health" OR "Guideline, Health Planning" OR "Guidelines, Health Planning" OR "Health Planning Guideline" OR "Planning Guideline, Health" OR "Planning Guidelines, Health" OR "Guidelines for Health Planning. Controlled descriptors for Concept (C): "Health Facility Administration" OR "Public Health Administration" OR "Hospital Administration" OR "Health Services Administration". Uncontrolled descriptors for Concept: "Administration, Health Facility" OR "Facility Administration, Health" OR "Administration, Public Health" OR "Administration, Hospital" OR "Hospital Organization and Administration" OR "Organization and Administration, Hospital" OR "Administration, Health Services". Controlled descriptors for Context(C): "Mental Health" OR "Mental Health Services". Uncontrolled descriptors for Context:- "Health Services, Mental" OR "Health Service, Mental" OR "Mental Health Service" OR "Service, Mental Health" OR "Services, Mental Health".

The inclusion criteria for the articles retrieved from the database search were as follows: publications in languages mastered by the authors (English, Spanish and Portuguese); publications in the last 15 years (2003-2018) that were determined by their compatibility with the studies used in the WHO Mental Health Action Plan 2013-2020(1); published articles; qualitative and quantitative studies; the search sources may include any existing literature, namely primary research studies, systematic reviews, meta-analyses, studies linked to countries that have a public health system, and that the search be left as "open", allowing for the inclusion of all documents and justifications.

The exclusion criteria were given as follows: studies out of the desired integrative review; articles and documents that were not available in an electronic format or could not be accessed due to payment restrictions; articles related to countries that do not have a public health system; indicators of other health areas, websites, and advertisements in the media.

4: Data selection and storage. The organization of this process was made using two software programs, Mendeley (https://www.mendeley.com) and Rayyan (https://rayyan. qcri.org/), to manage and share research documents.

5: Collating, summarizing and reporting results. This step was the elaboration of a narrative synthesis describing the objectives and the purposes of the selected and reviewed documents, the concepts adopted and the results related to the issue of this review ${ }^{(17)}$. 
6: Results Analysis - Discussion. Finally, the articles obtained were analyzed between high-income countries (HICs) and LMICs as well as how they make use of MHIs in the management of services, financial resources and policies for the creation and implementation of MHIs.

This study is part of a larger international multicenter project involving researchers from the Ribeirão Preto Medical School and the Ribeirão Preto School of Nursing in Brazil, in partnership with the Polytechnic Institute of Leiria, Portugal. Thus, it is important to highlight that the steps described above were made with the participation of these researchers.

\section{Results}

We executed a structured search with defined strategies in the respective database platforms, along with controlled descriptors, uncontrolled descriptors, and keywords. It resulted in 929 papers among all databases and, after a duplicity analysis, 125 papers were removed. Then, using the procedures defined and refined from the inclusion and exclusion criteria combined with this study's GQ, an initial screening of the papers' titles and abstracts resulted in an exclusion of 804 records. Afterward, a full-text reading was performed on the papers left aiming to identify articles that addressed the GQ of this study. As a result of this step, a total of 22 articles were selected to be part of the Integrative Review. The selection criteria applied in this Integrative Review were performed by two researchers and submitted to a third one for review.

In order to organize reports and present systematic results according to the proposed approach, we used the Preferred Reporting Items for Systematic Reviews and MetaAnalyses (PRISMA). The screening of the selected studies in this study was summarized in the 4-step prism flowchart: identification, screening, eligibility, and included(18).

A brief presentation of this process and its characteristics can be seen in the PRISMA flow chart presented in Figure 1.

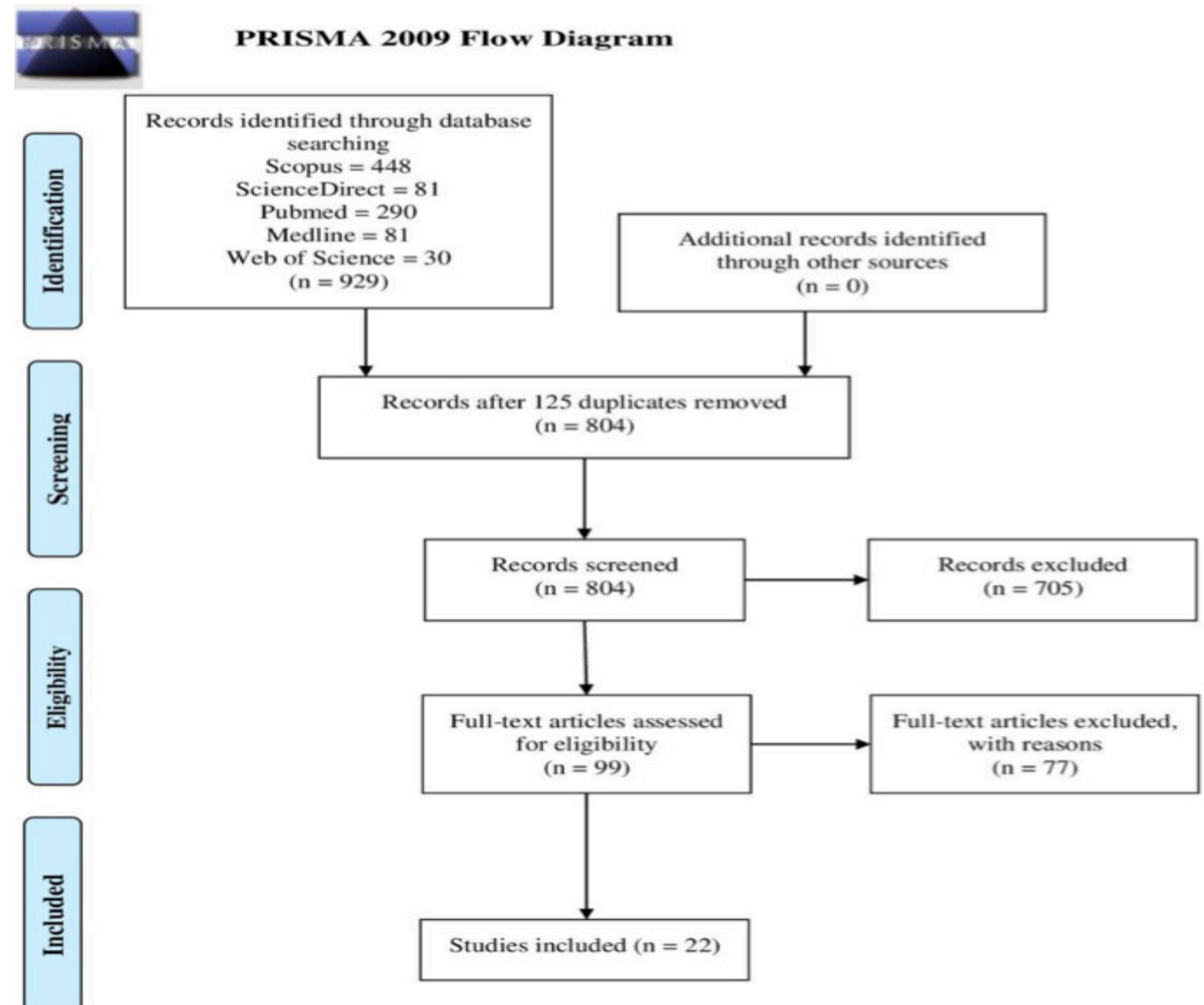

Figure 1 - PRISMA 2009 Flow Diagram adapted(17) 
We present the analysis of the 22 studies identified in the database search. Initially, we divided the findings into two main groups: HICs (54\%) and LMICs (46\%). Also, the studies were organized in chronological order. In the first group, we present studies conducted for HICs, while the main characteristics of the second group are LMICs. Then, each group was classified into conforming subgroups in characteristic of the population studied, i.e., studies involving a group of countries, countries or regions of countries were categorized. Next, we showed a more detailed analysis of the studies found, following the previous division described, in accordance with their income level.

Considering the studies in the main group of HICs, we identified 5 papers related to the group of countries, the papers belonging to the WHO, the Organization for Economic Cooperation and Development (OECD), the Statistical Office of the European Communities (Eurostat) and the Intercontinental Marketing Services (IMS) $)^{(19-23)}$, as shown in Figure 2 below.

\begin{tabular}{|c|c|c|c|}
\hline Study & Study Objective & Territorial dimension & $\begin{array}{l}\text { Implementation of } \\
\text { indicators }\end{array}$ \\
\hline $\begin{array}{l}\text { Psychosocial well-being and } \\
\text { psychiatric care in the European } \\
\text { Communities: analysis of macro } \\
\text { indicators }^{(19)}\end{array}$ & $\begin{array}{l}\text { To review macro indicators capable } \\
\text { of providing a synthetic description } \\
\text { of mental health status and the } \\
\text { availability of psychiatric care in } \\
\text { European countries }\end{array}$ & $\begin{array}{l}\text { Europe (OECD, EUROSTAT }{ }^{\ddagger} \text { and } \\
\left.\text { IMS }{ }^{\S}\right)\end{array}$ & $\begin{array}{l}\text { The authors do not report } \\
\text { the experience of using the } \\
\text { indicators in the management }\end{array}$ \\
\hline $\begin{array}{l}\text { New perspectives of mental health } \\
\text { service }^{(20)}\end{array}$ & $\begin{array}{l}\text { The study searches methodologies for } \\
\text { the use of health indicators, based on } \\
\text { characteristics of the users of health } \\
\text { services }\end{array}$ & $\begin{array}{l}\text { Italy, Austria, Estonia, Finland, France, } \\
\text { Italy, Spain, Norway, Romania and UK } \\
\text { (England, Scotland, Wales and } \\
\text { Northern Ireland) }\end{array}$ & $\begin{array}{l}\text { The authors do not report } \\
\text { the experience of using the } \\
\text { indicators in the management }\end{array}$ \\
\hline $\begin{array}{l}\text { Monitoring of mental health care } \\
\text { at the system level: country } \\
\text { profiles and } E U^{*} \text { country status }{ }^{(21)}\end{array}$ & $\begin{array}{l}\text { To provide a descriptive overview of } \\
\text { Quality Monitoring Programs status in } \\
\text { European countries }\end{array}$ & $\begin{array}{l}\text { England, Denmark, France, Germany, } \\
\text { Italy, Netherlands, Portugal, and } \\
\text { Sweden }\end{array}$ & Partial implementation \\
\hline $\begin{array}{l}\text { Reporting and use of OECD } \\
\text { Quality Indicators for Health Care } \\
\text { at the national and regional levels } \\
\text { in } 15 \text { countries }^{(22)}\end{array}$ & $\begin{array}{l}\text { To explore reports on the use of } \\
\text { quality indicators in OECD member } \\
\text { countries }\end{array}$ & $\begin{array}{l}\text { Belgium, Canada, Czech Republic, } \\
\text { France, Germany, Ireland, Israel, } \\
\text { Latvia, Netherlands, Norway, New } \\
\text { Zealand, Slovakia, Sweden, United } \\
\text { States and UK (England, Scotland, } \\
\text { Wales and Northern Ireland) } \\
\end{array}$ & Partial implementation \\
\hline $\begin{array}{l}\text { UK Quality Indicator Project }{ }^{\circledR} \\
\text { (UK QIP) and the UK (England, } \\
\text { Scotland, Wales and Northern } \\
\text { Ireland) independent health care } \\
\text { sector: a new development }{ }^{(23)}\end{array}$ & $\begin{array}{l}\text { To describe the implementation of the } \\
\text { UK Quality Indicators Project in the } \\
\text { health sector }\end{array}$ & $\begin{array}{l}\text { UK (England, Scotland, Wales and } \\
\text { Northern Ireland) }\end{array}$ & Implementation in use \\
\hline
\end{tabular}

${ }^{*} \mathrm{EU}=$ European Union; ${ }^{+} \mathrm{OCDE}=$ Organization for Economic Cooperation and Development; ${ }^{\ddagger}$ EUROSTAT = Statistical Office of the European Communities; §IMS = Intercontinental Marketing Services

Figure 2 - High-income regions

The remaining studies consisted of 6 related to $\mathrm{HICs}^{(24-29)}$ and one related to a high-income specific region ${ }^{(30)}$, as shown in Figure 3 below.

\begin{tabular}{|c|c|c|c|}
\hline Study & Study Objective & $\begin{array}{c}\text { Territorial } \\
\text { dimension }\end{array}$ & Implementation of indicators \\
\hline $\begin{array}{l}\text { Overview of the healthcare system in the } \\
\text { Czech Republic }{ }^{(24)}\end{array}$ & $\begin{array}{l}\text { To describe the Czech mental health } \\
\text { system through population indicators }\end{array}$ & Czech Republic & $\begin{array}{l}\text { The authors do not report the } \\
\text { experience of using the indicators } \\
\text { in the management }\end{array}$ \\
\hline $\begin{array}{l}\text { Development of Mental Health Indicators in } \\
\text { Korea }^{(25)}\end{array}$ & $\begin{array}{l}\text { To develop ways to measure the state } \\
\text { of mental health in Korea by analyzing } \\
\text { indicators in other regions }\end{array}$ & Korea South & Indicators were only selected \\
\hline $\begin{array}{l}\text { Call for information, call for quality in mental } \\
\text { health care }{ }^{(26)}\end{array}$ & $\begin{array}{l}\text { To build a model to improve the quality of } \\
\text { mental health services mediation system at } \\
\text { regional and local levels }\end{array}$ & Italy & $\begin{array}{l}\text { The authors do not report the } \\
\text { experience of using the indicators } \\
\text { in the management }\end{array}$ \\
\hline $\begin{array}{l}\text { Size Matters - Determinants of Modern, } \\
\text { Community-Oriented Mental Health } \\
\text { Services }^{(27)}\end{array}$ & $\begin{array}{l}\text { To explore the quality and quantity of } \\
\text { substance abuse-related mental health } \\
\text { services, and evaluate the correlation } \\
\text { between the needs of the population and } \\
\text { the availability of those services }\end{array}$ & Finland & Implementation in use \\
\hline $\begin{array}{l}\text { Quality indicators for the referral process } \\
\text { from primary to specialized mental health } \\
\text { care: an explorative study in accordance with } \\
\text { the RAND* appropriateness method }{ }^{(28)}\end{array}$ & $\begin{array}{l}\text { To develop quality indicators to detect the } \\
\text { impact of quality of primary care referral } \\
\text { information to specialized mental health } \\
\text { care has on the quality of mental health } \\
\text { services }\end{array}$ & Norway & $\begin{array}{l}\text { The authors do not report the } \\
\text { experience of using the indicators } \\
\text { in the management }\end{array}$ \\
\hline
\end{tabular}


(Figure 3 continuation...)

\begin{tabular}{|l|l|l|l|}
\hline \multicolumn{1}{|c|}{ Study } & \multicolumn{1}{|c|}{ Study Objective } & \multicolumn{1}{c|}{$\begin{array}{c}\text { Territorial } \\
\text { dimension }\end{array}$} & \multicolumn{1}{c|}{ Implementation of indicators } \\
\hline $\begin{array}{l}\text { Mental health quality, outcome measurement, } \\
\text { and improvement in Germany }{ }^{(29)}\end{array}$ & $\begin{array}{l}\text { To describe the most recent results of } \\
\text { quality assurance programs for mental } \\
\text { health services in Germany }\end{array}$ & Germany & Implementation in use \\
\hline $\begin{array}{l}\text { Composing a Core Set of Performance } \\
\text { Indicators for Public Mental Health Care: A } \\
\text { Modified Delphi Procedure }{ }^{(30)}\end{array}$ & $\begin{array}{l}\text { To describe the development of a set of } \\
\text { performance indicators that are feasible, } \\
\text { meaningful and useful for assessing the } \\
\text { quality of the public mental health system in } \\
\text { Amsterdam }\end{array}$ & Netherlands & Pilot implementation \\
\hline
\end{tabular}

*RAND = The RAND/UCLA Appropriateness Method (RAM) was developed in the mid-1980s, as part of the RAND Corporation/University of California Los Angeles (UCLA) Health Services Utilization Study, primarily as an instrument to enable the measurement of the overuse and underuse of medical and surgical procedures

Figure 3 - High-income countries

For the other group of selected studies, we identified 7 articles related to groups of LMICs(31-37), as shown in Figure 4 below.

\begin{tabular}{|c|c|c|c|}
\hline Study & Study Objective & Territorial dimension & Implementation of indicators \\
\hline $\begin{array}{l}\text { Financing mental health services in low- } \\
\text { and middle-income countries }{ }^{(31)}\end{array}$ & $\begin{array}{l}\text { To evaluate the impact of health } \\
\text { care financing deals on the } \\
\text { efficient and equitable use of } \\
\text { mental health services }\end{array}$ & $\begin{array}{l}\text { Azerbaijan, Bulgaria, Georgia, } \\
\text { Lithuania, Kyrgyzstan, Pakistan, } \\
\text { Nepal, Thailand, Malaysia, Chile, } \\
\text { Kenya, Zambia }\end{array}$ & $\begin{array}{l}\text { The authors do not report } \\
\text { the experience of using the } \\
\text { indicators in the management }\end{array}$ \\
\hline $\begin{array}{l}\text { Scale up services for mental disorders: a } \\
\text { call for action }{ }^{(32)}\end{array}$ & $\begin{array}{l}\text { To improve mental health services } \\
\text { through the search for financing } \\
\text { and monitor this improvement } \\
\text { through indicators }\end{array}$ & $\begin{array}{l}\text { Chile, Albania, Ethiopia, Thailand, } \\
\text { China (Hunan Province), Iran, } \\
\text { Nepal, Morocco, Nigeria, Ukraine, } \\
\text { Vietnam, Paraguay }\end{array}$ & Partial implementation \\
\hline $\begin{array}{l}\text { Mental health systems in countries: } \\
\text { where are we now? } ?^{(33)}\end{array}$ & $\begin{array}{l}\text { To analyze ways to improve health } \\
\text { systems in low- and middle-income } \\
\text { countries }\end{array}$ & Brazil, India and South Africa & Partial implementation \\
\hline $\begin{array}{l}\text { Three models of community mental } \\
\text { health services in low-income } \\
\text { countries }^{(34)}\end{array}$ & $\begin{array}{l}\text { To compare three models of } \\
\text { community mental health services } \\
\text { in low-income settings }\end{array}$ & Nigeria, Philippines, and India & $\begin{array}{l}\text { The authors do not report } \\
\text { the experience of using the } \\
\text { indicators in the management }\end{array}$ \\
\hline $\begin{array}{l}\text { Situational analysis: preliminary regional } \\
\text { review of the Mental Health Atlas } 2014^{(35)}\end{array}$ & $\begin{array}{l}\text { To consolidate the data provided } \\
\text { for the Atlas } 2014 \text { questionnaire by } \\
\text { the Member States of the Eastern } \\
\text { Mediterranean region }\end{array}$ & $\begin{array}{l}22 \text { Member States of the Eastern } \\
\text { Mediterranean Region }\end{array}$ & Partial implementation \\
\hline $\begin{array}{l}\text { Indicators for routine monitoring of } \\
\text { effective mental health coverage in Low- } \\
\text { and Middle-Income Countries (LMIC) } \\
\text { environments: a Delphi study }(36)\end{array}$ & $\begin{array}{l}\text { To identify indicators for the } \\
\text { measurement of effective coverage } \\
\text { of mental health treatment through } \\
\text { a Delphi Study }\end{array}$ & $\begin{array}{l}\text { Ethiopia, India, Nepal, Nigeria, } \\
\text { South Africa and Uganda }\end{array}$ & $\begin{array}{l}\text { The authors do not report } \\
\text { the experience of using the } \\
\text { indicators in the management }\end{array}$ \\
\hline $\begin{array}{l}\text { Evaluating capacity-building for mental } \\
\text { health system strengthening in low- and } \\
\text { middle-income countries for service } \\
\text { users and caregivers, service planners } \\
\text { and researchers }{ }^{(37)}\end{array}$ & $\begin{array}{l}\text { To evaluate the impact of human } \\
\text { resources training in low- and } \\
\text { middle-income countries }\end{array}$ & $\begin{array}{l}\text { Ethiopia, India, Nepal, Nigeria, } \\
\text { South Africa and Uganda }\end{array}$ & $\begin{array}{l}\text { The authors do not report } \\
\text { the experience of using the } \\
\text { indicators in the management }\end{array}$ \\
\hline
\end{tabular}

Figure 4 - Low-income and middle-income regions

We also identified one study that describes LMICs individually(38), while the other two refer to specific regions of LMICs $^{(39-40)}$. As shown in Figure 5 below:

\begin{tabular}{|l|l|l|l|}
\hline \multicolumn{1}{|c|}{ Study } & \multicolumn{1}{|c|}{ Study Objective } & \multicolumn{1}{c|}{$\begin{array}{c}\text { Territorial } \\
\text { dimension }\end{array}$} & \multicolumn{1}{|c|}{$\begin{array}{c}\text { Implementation of } \\
\text { indicators }\end{array}$} \\
\hline $\begin{array}{l}\text { Public sector mental health systems in South } \\
\text { Africa: Inter-provincial comparisons and policy } \\
\text { implications }\end{array}$ & $\begin{array}{l}\text { To document current levels of provision of } \\
\text { public health mental health services in South } \\
\text { Africa and to compare services between } \\
\text { provinces }\end{array}$ & South Africa \\
\hline $\begin{array}{l}\text { Evaluation of results and impact of the first phase } \\
\text { of a community based mental health model in } \\
\text { localities in Bogotá, D.C. }{ }^{(39)}\end{array}$ & $\begin{array}{l}\text { To evaluate the impact of the Community } \\
\text { Based Mental Health Model through indicators }\end{array}$ & Colombia & Implementation in use \\
\hline $\begin{array}{l}\text { Development of mental health indicators at the } \\
\text { district level in Madhya Pradesh, India: mixed } \\
\text { methods study }\end{array}$ & $\begin{array}{l}\text { To develop a basic set of indicators to monitor } \\
\text { mental health in primary care settings through a } \\
\text { Mixed Methods Study }\end{array}$ & India & Implementation in use \\
\hline
\end{tabular}

Figure 5 - Low-income and middle-income countries 
According to the subject matter presented, we identified that 5 studies effectively reported the experience of using MHIs and 3 of them described high-income environments(23,27,29,38-39). Another 5 studies reported partial implementation of MHIs(21-22,32-33,35). An additional 9 papers didn't report the use or implementation of developed indicators ${ }^{(19-20,24,26,28,31,34,36-37)}$. Another study presented only the process of selection of indicators ${ }^{(25)}$. The last two studies were about an implementation pilot of $\mathrm{MHIs}^{(30)}$ and a discussion of MHIs for implementation(40).

Studies related to HICs. A study conducted from 1980 to 2000 in a group of 16 countries belonging to the WHO, OECD; Eurostat and IMS showed the use of macro indicators. However, it showed that the official resources for European countries indicate a lack of efficient institutional information and the need to improve the quality of $\mathrm{MH}$ services in European countries ${ }^{(19)}$.

Another study pointed out the profile of 8 countries in Europe, which have programs to monitor the quality of $\mathrm{MH}$ care implemented at their system level. Moreover, Italy and Germany are in the process of developing and implementing such programs, while in Portugal a Quality Monitoring Program in Mental Health Care (QMPMHC) started to be implemented in 2016 (21). Currently, in Portugal, only general indicators implemented for healthcare use monitoring. Specific quality monitoring in mental healthcare is to be implemented. All countries, except the Netherlands and France, use administrative data as the main source of indicators. This shows the relevance of reliable available databases, such as those provided by claims data or health care use records, to facilitate the implementation of indicator-based quality assurance. Indicators that are constructed from administrative data are more likely to measure what is easier to measure, rather than what is relevant. Denmark, England, Germany, Holland, and Portugal also make use of reported clinical data, while the Netherlands only uses clinical or patient data. Evidence shows that the best results in quality monitoring systems are obtained if monitoring and feedback methodologies are used(21).

The Organization for Economic Co-operation and Development (OECD) conducted a study between June and December of 2014 among its 37 member countries(22). The objective of this particular study was to explore the reporting and use of OECD Health Care Quality Indicators (HCQI) in its member-states. The reports from these countries were most frequently focused on specific diseases and attention systems/indicators in the sector. The only indicators specific to the care of mental disorders in the study were unplanned hospital readmissions for mental disorders, unplanned schizophrenia re-admissions (same or different hospital), unplanned bipolar disorder re-admissions (same or different hospital) and excess of mortality due to mental disorders (schizophrenia/ bipolar disorders). None of the reports from the countries contained responses for all four of the indicators proposed by the study, and only Belgium and Canada referred to the treatment of mental disorders. $\mathrm{MH}$ care and patient care with indicators of outpatient care were reported with less presence. The least mentioned indicator was "excess mortality due to mental disorders"(22).

In a more specific study for HICs, the Italian experience in the use of clinical indicators is uneven, although Italy's psychiatric reform in 1978 and recent legislation have delegated responsibility for planning, coordinating and delivering $\mathrm{MH}$ care to regions ${ }^{(26)}$. After 30 years of psychiatric reform, inequalities still remain in terms of resources and provision of services and in terms of information technology and the use of information systems. Still, in HICs, we have the Netherlands that sought to develop performance indicators seeking to improve the $\mathrm{MH}$ system. However, the results of this study focused on a pilot implementation of $\mathrm{MHIs}^{(30)}$. In Norway, a study published in 2004 aimed to develop a set of quality indicators to detect the impact on the quality of $\mathrm{MH}$ services. Focus group participants emphasize that the local context may have implications for the interpretation of indicator data and pointed out the difficulties in reaching the numerator and denominator and in defining the quality indicators of $\mathrm{MH}$ services. Thus, the study did not inform the implementation and use of the selected quality indicators ${ }^{(28)}$.

Studies related to LMICs. The first study in this group showed that more than $85 \%$ of the world's population lives in 153 LMICs, of which $20-30 \%$ do not have MH policies, programs, and legislation. Within the WHO regions, $80 \%$ of the 191 countries had an $\mathrm{MH}$ policy or program and $70 \%$ had $\mathrm{MH}$ legislation. The analyzation between regions shows important differences, for example, $92 \%$ of the countries belonging to the European region have an $\mathrm{MH}$ policy, program and/or legislation. However, only $55 \%$ of the Eastern Mediterranean Region (EMR) countries have an $\mathrm{MH}$ policy, program and/or legislation ${ }^{(33)}$.

The EMR group of countries has 11 LMICS countries that do not have an MH policy, program and/or legislation. In the Africa and Southeast Asia regions, a total of $70 \%$ and $50 \%$ of their countries, respectively, spend less than $1 \%$ of their health budget on $\mathrm{MH}$ care. While $60 \%$ of the European countries spend more than $5 \%$ of their health budget on $\mathrm{MH}$ care. Only three African countries reported spending more than $5 \%$ of their $\mathrm{MH}$ financial resources ${ }^{(33)}$.

Another study finding is that the treatment gap for people with $\mathrm{MH}$ problems in LMICs is marked by the number of people who need care and those who receive such care. Moreover, a recent study aimed to improve $\mathrm{MH}$ outcomes in environments from six LMICs - Ethiopia, 
India, Nepal, Nigeria, South Africa and Uganda - in which they seek evidence and capacity to improve the health system, including the development, use and monitoring of indicators ${ }^{(36,41)}$.

Through a 10-year study, it was estimated that an additional investment of up to USD 20 per person/year would be needed for low-income countries, and of up to USD 30 for middle-income countries, which would result in a target expense of USD 2 and USD 3-4 per person, respectively. Compared to other investments, for example, the estimated total costs of increasing the neonatal health care package to $90 \%$ coverage was estimated at USD 5-10 per capita. Meanwhile, the cost of universal provision access to basic health services has been estimated at more than USD 30 per person per year(32).

Another study showed that 22 Member States in the EMR have independent $\mathrm{MH}$ policies that have been updated over the past 10 years. Legislation needs to be reviewed among $\mathrm{MH}$ policies by international human rights instruments and indicated that they are partially implemented(35). Countries from the region have the government as its main funding source (77\%). However, in the remaining countries, the main funding source can be households ( 2 countries), non-government organizations ( 1 country) or unknown ( 2 countries did not report) ${ }^{(35)}$.

\section{Discussion}

In all selected studies, the authors point to the relevance of using MHIs. According to the WHO guidelines in their Action Plan, several countries have attempted to define an appropriate set of indicators in the practice of $\mathrm{MH}$ services ${ }^{(1,35)}$. However, the results shown by MHIs have different uses for management, policy and service improvement ${ }^{(22,35)}$. Also, some countries are involved in the discussion process and in gathering the necessary indicators ${ }^{(21,33)}$. Nevertheless, some initiatives for the implementation of MHIs are in the process of partial implementation or in the implementation of pilot projects, suggesting that the effectiveness of these indicators is still unknown ${ }^{(26)}$. In LMICs countries, the research studies on MHIs were performed with many difficulties due to: lack of basic MH services; financial resources; legislation and political interest; $\mathrm{MH}$ management guidelines; and MH data integration systems ${ }^{(36,41-42)}$.

In the last decade, global $\mathrm{MH}$ has emerged as an important area of expression and research with the need for the development of $\mathrm{MH}$ services in middle-income countries. However, when comparing the health financial resources employed in $\mathrm{MH}$, it is a mistake to believe that improved $\mathrm{MH}$ care is only needed in poorer countries. The overall understanding of health should be about improving $\mathrm{MH}$ everywhere, including HICs. Although these countries have state-planned systems, they create inefficient $\mathrm{MH}$ services and make decisions that do not adequately involve those who use the services, making them inaccessible and indifferent ${ }^{(43)}$.

Outcome quality indicators are only occasionally used to analyze $\mathrm{MH}$ services, and that is because most jurisdictions do not have clinical data systems to meaningfully incorporate indicators among $\mathrm{MH}$ providers. Nevertheless, the effectiveness of the health services remains unknown ${ }^{(44)}$.

A project in France used patient-reported experience to measure the quality of admissible $\mathrm{MH}$ care for adult patients with $\mathrm{MH}$ disorders. These measures converged on the availability, diversity, and capacity of $\mathrm{MH}$ care resources but they do not include "what matters to patients". Other initiatives have been suggested to represent patients' views, such as the patient outcome information system. This work has been of great interest in France, where they have been reporting significant regional disparities in the $\mathrm{MH}$ system, without significant change, in recent decades ${ }^{(45)}$.

The process of implementing MHIs is a difficult task even for European countries. Portugal can be used as an example, with its National Health Plan being carried out throughout the 2017-2020 period; however, MHIs have not been implemented using proposals made by the Working Group. However, these proposed measures do not have an integrated strategy for the promotion and prevention of $\mathrm{MH}$. According to the report, these changes will only be possible if they are developed within the framework of coordination teams that have the capacity for action at the inter-sectorial level(46).

Moreover, this is a particular concern in LMICs, where more than $70 \%$ of mental illnesses occur. Poor access to $\mathrm{MH}$ services has been highlighted, ranging from less than $50 \%$ to less than $10 \%$ in many countries. In LMICs, the difference between those in need of treatment and resource availability is almost $90 \%{ }^{(47)}$.

In the case of Brazil, India and South Africa, a study points out that the financial resources earmarked are very scarce and that they have inadequate human resources and infrastructure for $\mathrm{MH}$. In the study, India reported that the national program was implemented only in small pockets (locations), after two decades of its acceptance, due to a lack of budget allocation for national use. In the case of South Africa, the study suggested that $\mathrm{MH}$ policy and legislation do not automatically translate into adequate $\mathrm{MH}$ services if they are not clearly defined by a comprehensive national program(33). In Brazil, important advances occurred in the 1980s, such as changes in politics and strengthening of the workforce. This resulted in a major reform of the $\mathrm{MH}$ system; changes in care delivery with the creation of new Community Psychosocial 
Centers (CAPS); and specialized $\mathrm{MH}$ services to provide outpatient care ${ }^{(12,48)}$. However, until recently, the only specific indicator for specialized MH service evaluation used in Brazil was the number of CAPS, while other indicators for $\mathrm{MH}$ aspects of primary care were also computed by the Program for Improving Access and Quality in Primary Care $(\mathrm{PMaQ})^{(42)}$. Nowadays, Brazil has been utilizing an indicator defined through the Inter-Federative Pact 20172021 , which refers to an action set of systematic matrices performed by the CAPS in partnership with primary care teams ${ }^{(49)}$.

Political reforms in the country and the commitment of health professionals to provide care in the primary health care system were the main facilitators for their success. However, many obstacles need to be overcome, concerns such as unequal distribution and coverage of community services in all regions, as well as the government's failure to increase resources for $\mathrm{MH}$ care remain major challenges. The effect of changes in the policy of providing $\mathrm{MH}$ care throughout Brazil needs to be evaluated regularly to improve and tune the system ${ }^{(12,42)}$. Therefore, the existing Brazilian indicators in $\mathrm{MH}$ cannot support consistent assessments of the model adopted in recent years and it is necessary to create indicators that cover all $\mathrm{MH}$ aspects of the population.

Some obstacles are pointed out in the literature on the use of indicators and difficulties in their implementation, professionals and managers view these indicators as threats, due to their unreliability, and as tools to penalize poor performance, including fear of area-based financial penalties and the integrative of professional control. Other issues indicate some distrust in the use of government-associated evaluators, lack of diagnoses defined in graphs, and difficulties to define intervention limits. Important financial issues emerge when discussing the use of indicators such as lack of equipment and internet access. The indicator generation is a costly task that requires intensive work and outside staff, this includes the need for computer training and increased workload as well as predefined routines and protocols.

Some other possible issues are as follows: information services may not be recorded in medical records or are difficult to find; lack of clarity and agreement on data entry; lack of time for planning professionals; and lack of staff approach to adjust to the changes of using indicators ${ }^{(50)}$.

For $\mathrm{MH}$ to find strong and widely agreed upon indicators of health and mental illness, there must be an improvement in the quality of care and in the attention in health services. Our results reinforce the importance of the indicators in all phases of the mental health-disease process and, therefore, to the entire network of health services. With these results, it seems important that specialized psychiatric prevention services implement health promotion programs specifically targeting psychiatric patients ${ }^{(20,51)}$.

A limitation of this review is that it should involve a detailed search of the normative documents, we only consulted and compared data found in scientific papers, there were difficulties in finding data sources with indicator information, calculation method and information systems of each country. A complementary work to this study is being carried out to obtain MHIs that suit Brazilian Health Information Systems and that can be implemented using the available data(52).

A strength to this review is that it shows that, by extracting knowledge on the use of a set of MHIs, it is possible to understand the implementation phase of indicators in different regions of the world and to compare them with each other. The MHI initiatives of several countries were in the implementation or development phase and this reflects the lack of maturity and consistency in the application of MHIs in most countries. Based on the MHIs evaluated in this study, we observe that there is no consensus regarding their use for $\mathrm{MH}$ management. In addition, we confirm the previous findings that there is no consensus on the definition, method of calculation, and management level of the indicators that are used.

\section{Conclusion}

The main findings of this review show that it is unusual to find a descriptive comparison of qualitymonitoring programs at the system level in the technicalscientific literature related to $\mathrm{MH}$. This occurs not only because such systems are rare or in development, but also because most programs are managed by national public agencies whose purpose is not to publish results in the scientific literature. Global initiatives are underway and seek to expand $\mathrm{MH}$ services to address the treatment and care gap.

Indicators are important information tools to map advances, setbacks or stagnation in different aspects and sectors of society. An analysis of indicators by the public and private health financing systems has not been found even in countries that have both systems. Indicators for each system may present relevant differences for analysis. In this sense, this review contributes to this scenario by extracting knowledge and establishing an updated framework on the use of MHI for care and management.

When we mention the importance of using indicators, we point out that they are intended to help individuals, understand the performance of community health services, and provide information easily and conveniently to reflect changes in time and to assess 
appropriate service performance to effectively meet customer needs. In developing indicators, patients and the integrative of indicators seek to understand $\mathrm{MH}$ problems, including mental disorders; resources, skilled labor, facilities and finances; MH services; risks; protective factors, and so on. They enhance MH status, factors, system, and quality of $\mathrm{MH}$ services to include prevention, treatment, ongoing management, and early interventions. Developed countries invest in MHIs systematically based on theoretical foundations, such as national projects, that not only assess the population's $\mathrm{MH}$ status and monitor trends, but also provide scientific research to policymakers as well as monitor processes and policy outcomes. Indicators are useful screening tools for potential problems in preventive and primary care. They also determine if there is a quality problem and the need for further analysis on a given topic.

This scenario suggests the need for a set of indicators to be standardized by the WHO, serving as an evidencebased guide to best practices available. Also, we have suggested more flexibility and adaptability, taking into account the reality of each country. To achieve this goal, the development of indicators must be carried out by professionals within the entire health service network.

\section{Acknowledgments}

To all the people who participated in this paper.

\section{References}

1. World Health Organization. Mental health action plan 2013 - 2020. [Internet]. Geneva: WHO; 2013 [cited Jan 2, 2020]. Available from: https://www.who.int/mental_ health/publications/action_plan/en/

2. Lima IB, Yamada DB, Yoshiura VT, Lance RC, Rodrigues $L M L$, Vinci ALT, et al. Proposal for selection of mental health indicators in the management of health networks: from heuristic to process modeling. Procedia Comput Sci. 2018;138:185-90. doi: 10.1016/j.procs.2018.10.026 3. Anderson KK, Fuhrer R, Schmitz N, Malla AK. Determinants of negative pathways to care and their impact on service disengagement in first-episode psychosis. Soc Psychiatry Psychiatr Epidemiol. 2012;48(1):125-36. Available from: https://doi.org/10.1007/s00127-0120571-0

4. World Health Organization. Mental Health Atlas 2014. [Internet]. Geneva: WHO; 2015 [cited Jan 2, 2020]. Available from: https://apps.who.int/iris/ bitstream/handle/10665/178879/9789241565011_eng. pdf?sequence $=1$

5. World Health Organization. Mental Health Atlas 2017. [Internet]. Geneva: WHO; 2018 [cited Jan 2, 2020].
Available from: https://apps.who.int/iris/bitstream/han dle/10665/272735/9789241514019-eng.pdf?ua=1

6. Vigo D, Thornicroft G, Atun R. Estimating the true global burden of mental illness. Lancet Psychiatry. 2016;3(2):171-8. doi: https://doi.org/10.1016/S22150366(15)00505-2

7. Bauer MS. A Review of Quantitative Studies of Adherence to Mental Health Clinical Practice Guidelines. Harvard Rev Psychiatry. 2002;10(3):138-53. doi: 10.1080/10673220216217

8. Docherty M, Shaw K, Goulding L, Parke H, Eassom $\mathrm{E}$, Ali $\mathrm{F}$, et al. Evidence-based guideline implementation in low and middle income countries: lessons for mental health care. Int J Ment Health Syst. 2017 May;11(1). doi: 10.1186/s13033-016-0115-1

9. Kilbourne AM, Keyser D, Pincus HA. Challenges and Opportunities in Measuring the Quality of Mental Health Care. Can J Psychiatry. 2010;55(9):549-57. doi: 10.1177/070674371005500903.

10. Girlanda F, Fiedler I, Ay E, Barbui C, Koesters M. Guideline implementation strategies for specialist mental healthcare. Curr Opin Psychiatry. 2013;26(4):369-75. doi: 10.1097/yco.0b013e328361e7ae

11. Weinmann S, Koesters M, Becker T. Effects of implementation of psychiatric guidelines on provider performance and patient outcome: systematic review. Acta Psychiatr Scand. 2007;115(6):420-33. doi: 10.1111/j.1600-0447.2007.01016.x

12. Dantas CDR, Oda AMGR. Cartografia das pesquisas avaliativas de serviços de saúde mental no Brasil (20042013). Physis Rev Saude Colet. 2014;24(4):1127-79. doi: $10.1590 /$ s0103-73312014000400008

13. The Joanna Briggs Institute. The Joanna Briggs Institute Reviewers' Manual 2015. [Internet]. 2015 [cited Jan 2, 2020]. Available from: https://nursing.Isuhsc.edu/ JBI/docs/ReviewersManuals/Scoping-.pdf

14. Dal K, Mendes S, Cristina de Campos R, Silveira P, Galvão CM. Integrative Literature Review: A research method to incorporate evidence in health care and nursing. Texto Contexto Enferm. 2008;17(4):758-64. doi: 10.1590/S0104-07072008000400018

15. Arksey H, Omalley L. Scoping studies: towards a methodological framework. Int J Soc Res Methodol. 2005;8(1):19-32. doi: 10.1080/1364557032000119616 16. Medical Subject Headings. [Internet]. U.S. National Library of Medicine; National Institutes of Health [cited Jan 3 2020]. Available from: https://www.nlm.nih.gov/ mesh/meshhome.html

17. Butler A, Hall H, Copnell B. A Guide to Writing a Qualitative Systematic Review Protocol to Enhance Evidence-Based Practice in Nursing and Health Care. Worldviews Evid Based Nurs. 2016;13(3):241-9. doi: 10.1111/wvn.12134 
18. Moher D. Preferred Reporting Items for Systematic Reviews and Meta-Analyses: The PRISMA Statement. Ann Intern Med. 2009;151(4):264. doi: 10.7326/0003-4819151-4-200908180-00135

19. Carta MG, Kovess V, Hardoy MC, Brugha T, Fryers $T$, Lehtinen $V$, et al. Psychosocial wellbeing and psychiatric care in the European Communities: analysis of macro indicators. Soc Psychiatry Psychiatr Epidemiol. 2004;39(11):883-92. doi: 10.1007/s00127-004-0871-0 20. Amaddeo F, Tansella M. New perspectives of mental health service research. Epidemiol Psychiatr Sci. 2011;20(1):3-6. doi: 10.1017/s2045796011000047

21. Bramesfeld A, Amaddeo F, Caldas-De-Almeida J, Cardoso G, Depaigne-Loth A, Derenne R, et al. Monitoring mental healthcare on a system level: Country profiles and status from EU countries. Health Policy. 2016;120(6):70617. doi: $10.1016 /$ j.healthpol.2016.04.019

22. Rotar AM, Berg MJVD, Kringos DS, Klazinga NS. Reporting and use of the OECD Health Care Quality Indicators at national and regional level in 15 countries. Int J Qual Health Care. 2016;28(3):398-404. doi: 10.1093/intqhc/mzw027

23. Thomson R. UK Quality Indicator Project(R) (UK QIP) and the UK independent health care sector: a new development. International J Qual Health Care. 2004Jan;16(suppl_1):i51-i56. doi: 10.1093/intqhc/ mzh011.

24. Kinkorová J, Topolčan O. Overview of healthcare system in the Czech Republic. EPMA J. 2012;3(1). doi: 10.1007/s13167-012-0139-9

25. Han H, Ahn DH, Song J, Hwang TY, Roh S. Development of Mental Health Indicators in Korea. Psychiatry Invest. 2012;9(4):311. doi: 10.4306/pi.2012.9.4.311

26. Lora A. Call for information, call for quality in mental health care. Epidemiol Psychiatr Sci. 2012;22(1):9-13. doi: $10.1017 /$ s2045796012000716

27. Ala-Nikkola T, Pirkola S, Kontio R, Joffe G, Pankakoski M, Malin M, et al. Size Matters - Determinants of Modern, Community-Oriented Mental Health Services. Int J Env Res Pub Health. 2014;11(8):8456-74. doi: 10.3390/ ijerph 110808456

28. Hartveit M, Vanhaecht K, Thorsen O, Biringer E, Haug K, Aslaksen A. Quality indicators for the referral process from primary to specialised mental health care: an explorative study in accordance with the RAND appropriateness method. BMC Health Serv Res. 2017 Mar;17(1). doi: 10.1186/s12913-016-1941-1

29. Gaebel W, Janssen B, Zielasek J. Mental health quality, outcome measurement, and improvement in Germany. Curr Opin Psychiatry. 2009;22(6):636-42. doi: 10.1097/ yco.0b013e3283317c00

30. Lauriks S, Wit MASD, Buster MCA, Arah OA, Klazinga NS. Composing a Core Set of Performance Indicators for
Public Mental Health Care: A Modified Delphi Procedure. Admin Policy Ment Health. 2014 Sep;41(5):625-35. doi: 10.1007/s10488-013-0506-4

31. Dixon A, Mcdaid D, Knapp M, Curran C. Financing mental health services in low- and middle-income countries. Health Policy Plan. 2006;21(3):171-82. doi: 10.1093/heapol/czl004

32. Lancet Global Mental Health Group. Scale up services for mental disorders: a call for action. Lancet. 2007;370(9594):1241-52. doi: 10.1016/s01406736(07)61242-2

33. Jacob K, Sharan P, Mirza I, Garrido-Cumbrera M, Seedat S, Mari J, et al. Mental health systems in countries: where are we now? Lancet. 2007;370(9592):1061-77. doi: 10.1016/s0140-6736(07)61241-0

34. Cohen A, Eaton J, Radtke B, George C, Manuel B, Silva MD, et al. Three models of community mental health services in low-income countries. Int J Ment Health Syst. 2011;5(1):3. doi: 10.1186/1752-4458-5-3.

35. R G, Chew Z, Saeed K. Situational analysis: preliminary regional review of the Mental Health Atlas 2014. Eastern Mediterr Health J. 2015 Jan;12(7):467-76. doi: $10.26719 / 2015.21 .7 .467$

36. Jordans MJD, Chisholm D, Semrau M, Upadhaya $\mathrm{N}$, Abdulmalik J, Ahuja $\mathrm{S}$, et al. Indicators for routine monitoring of effective mental healthcare coverage in lowand middle-income settings: a Delphi study. Health Pol Plan. 2016;31(8):1100-6. doi: 10.1093/heapol/czw040 37. Hanlon C, Semrau M, Alem A, Abayneh S, Abdulmalik J, Docrat $S$, et al. Evaluating capacity-building for mental health system strengthening in low- and middle-income countries for service users and caregivers, service planners and researchers. Epidemiol Psychiatr Sci. 2017;27(1):310. doi: $10.1017 / s 2045796017000440$

38. Lund C, Kleintjes S, Kakuma R, Flisher AJ. Public sector mental health systems in South Africa: interprovincial comparisons and policy implications. Soc Psychiatry Psychiatr Epidemiol. 2009 Sep;45(3):393404. doi: 10.1007/s00127-009-0078-5

39. Hernandez LJ. Evaluación de resultados e impactos de un Modelo de Salud Mental Basado en la Comunidad en localidades de Bogotá, DC. Rev Salud Pública. 2003;5(3):272-83. doi: 10.1590/s012400642003000300004

40. Ahuja S, Gronholm PC, Shidhaye R, Jordans M, Thornicroft G. Development of mental health indicators at the district level in Madhya Pradesh, India: mixed methods study. BMC Health Serv Res. 2018;18(1). doi: 10.1186/ s12913-018-3695-4

41. Upadhaya N, Jordans MJD, Abdulmalik J, Ahuja $S$, Alem A, Hanlon C, et al. Information systems for mental health in six low and middle income countries: 
cross country situation analysis. Int J Ment Health Syst. 2016;10(1). doi: 10.1186/s13033-016-0094-2

42. Mendes MFDM, Rocha CMFD. Avaliação Em Saúde Mental: Uma Análise de Políticas Nacionais e Internacionais. Saúde Redes. 2016;2(4):352-9. doi: 10.18310/2446-4813.2016v2n4p352-359

43. Sashidharan SP, White R, Mezzina R, Jansen S, Gishoma D. Global mental health in high-income countries. Br J Psychiatry. 2016;209(1):3-5. doi: 10.1192/bjp. bp. 115.179556

44. Perlman CM, Hirdes JP, Barbaree H, Fries BE, Mckillop I, Morris JN, et al. Development of mental health quality indicators (MHQIs) for inpatient psychiatry based on the interRAI mental health assessment. BMC Health Serv Res. 2013 Oct;13(1). doi: 10.1186/1472-6963-13-15

45. Fernandes S, Fond G, Zendjidjian X, Michel $P$, Baumstarck K, Lancon C, et al. The Patient-Reported Experience Measure for Improving quality of care in Mental health (PREMIUM) project in France: study protocol for the development and implementation strategy. Patient Prefer Adherence. 2019;13:165-77. doi: 10.2147/ppa.s172100 46. Xavier M, Paixão I, Mateus P, Goldschmidt T, Pires P, Narigão $M$, et al. Relatório da Avaliação do Plano Nacional de Saúde Mental 2007-2016 e propostas prioritárias para a extensão a 2020. [Internet]. Lisboa: Serviço Nacional de Saúde; 2017 [Acesso 2 jan 2020]. Disponível em: https://www.sns.gov.pt/wp-content/uploads/2017/08/ RelAvPNSM2017.pdf

47. Alloh FT, Regmi P, Onche I, Teijlingen EV, Trenoweth S. Mental Health in low-and middle income countries (LMICS): Going beyond the need for funding. Health Prospect. 2018;17(1):12-7. doi: 10.3126/hprospect. v17i1.20351

48. Ministério da Saúde (BR). Portaria No-3.088, de 23 de dezembro de 2011. Institui a Rede de Atenção Psicossocial para pessoas com sofrimento ou transtorno mental e com necessidades decorrentes do uso de crack, álcool e outras drogas, no âmbito do Sistema Único de Saúde. Diário Oficial da União, 26 dez 2011. [Internet]. Available from: http://www.rio.rj.gov.br/ dlstatic/10112/5202308/4139572/PortariaN3.088Rede deAtencaoPsicossocial.pdf

49. Ministério da Saúde (BR). Pactuação Interfederativa 2017-2021: Fichas de Indicadores [Internet]. Brasil: MS; 2017 [Acesso 2 jan 2020]. Disponível em: http:// www.saude.df.gov.br/wp-conteudo/uploads/2017/11/ PACTUACAO-INTERFEDERATIVA-2017-2021.pdf
50. Addington D, Bs MB, Kyle T, Desai S, Wang J. Research Facilitators and barriers to implementing quality measurement in primary mental health care: systematic review Can Fam Physician. [Internet]. 2010 [cited Jan 2, 2020];56(12):1322-31. Available from: https://www.cfp. ca/content/56/12/1322.long

51. Mai Q, Holman CDJ, Sanfilippo FM, Emery JD. The impact of mental illness on potentially preventable hospitalisations: a population-based cohort study. BMC Psychiatry. 2011 Oct;11(1). doi: 10.1186/1471-244x11-163

52. Vinci ALT, Lima IB, Rijo RPCL, Alves D. Mental Health Indicators Set for Management and Evaluation of a Mental Healthcare Network: Implementation Feasibility Analysis, to Administration and Policy in Mental Health and Mental Health Services Research. Admin Pol Ment Health. Forthcoming 2019.

\section{Authors' Contribution:}

Study concept and design: Inacia Bezerra de Lima, Filipe Andrade Bernadi, Domingos Alves. Obtaining data: Inacia Bezerra de Lima, Filipe Andrade Bernadi, Diego Bettiol Yamada, Andre Luiz Teixeira Vinci, Rui Pedro Charters Lopes Rijo, Domingos Alves, Antonia Regina Ferreira Furegato. Data analysis and interpretation: Inacia Bezerra de Lima, Filipe Andrade Bernadi, Diego Bettiol Yamada, Andre Luiz Teixeira Vinci, Rui Pedro Charters Lopes Rijo, Domingos Alves, Antonia Regina Ferreira Furegato. Drafting the manuscript: Inacia Bezerra de Lima, Filipe Andrade Bernadi, Diego Bettiol Yamada, Andre Luiz Teixeira Vinci, Rui Pedro Charters Lopes Rijo, Domingos Alves, Antonia Regina Ferreira Furegato. Critical review of the manuscript as to its relevant intellectual content: Inacia Bezerra de Lima, Filipe Andrade Bernadi, Diego Bettiol Yamada, Andre Luiz Teixeira Vinci, Rui Pedro Charters Lopes Rijo, Domingos Alves, Antonia Regina Ferreira Furegato.

All authors approved the final version of the text. Conflict of interest: the authors have declared that there is no conflict of interest.

Received: Feb $16^{\text {th }} 2020$ Accepted: Jul $31^{\text {st }} 2020$

Associate Editor: Sueli Aparecida Frari Galera

Copyright $($ C) 2021 Revista Latino-Americana de Enfermagem This is an Open Access article distributed under the terms of the Creative Commons (CC BY).

This license lets others distribute, remix, tweak, and build upon your work, even commercially, as long as they credit you for the original creation. This is the most accommodating of licenses offered. Recommended for maximum dissemination and use of licensed materials.
Corresponding author:

E-mail: lima.inacia@gmail.com

(iD) https://orcid.org/0000-0003-3580-3244 